\title{
PORTA DE ENTRADA OU PORTA DE SAÍDA? FRACASSO ESCOLAR NO ENSINO MÉDIO SEGUNDO ESTUDANTES E COORDENADORES(AS) DE ESCOLAS EM RIBEIRÃO DAS NEVES, MG
}

\author{
Vanessa Lima Caldeira Franceschini \\ Consultora independente - Universidade Federal de Minas Gerais (UFMG), Belo Horizonte - MG, Brasil \\ Paula Miranda-Ribeiro"* \\ Universidade Federal de Minas Gerais (UFMG), Belo Horizonte - MG, Brasil \\ Marília Miranda Fortes Gomes ${ }^{* *}$ \\ Universidade de Brasília (UnB), Brasília - DF, Brasil
}

RESUMO: O objetivo deste artigo é entender as motivações para o fracasso escolar (infrequência, reprovação e abandono escolar) na primeira série do Ensino Médio e as maneiras de revertê-lo. Foram realizados grupos focais com estudantes (15 a 19 anos) e entrevistas semiestruturadas com coordenadores(as) em três escolas da Rede Estadual de Ribeirão das Neves em 2014. Os motivos para o fracasso escolar são trabalho, questões familiares (falta de acompanhamento escolar, necessidade de cuidar de irmãos, maridos, filhos), não ter dinheiro para ônibus, violência, falta de interesse nas aulas, professores ruins, uso de drogas, más companhias, bullying e ter tido reprovação anterior. Para reverter o fracasso escolar, é preciso haver ações do Estado (infraestrutura, salários melhores, programas de incentivo à permanência), da escola (professores mais bem-preparados/ motivados, novas práticas de ensino, diálogo entre diretoria e estudantes), da família (acompanhamento do desempenho escolar, participação em reuniões) e do próprio aluno (dedicação, atenção nas aulas).

Palavras-chave: Desempenho escolar. Reprovação. Abandono. Ensino Médio. Adolescentes.

\footnotetext{
"Doutora em Demografia pelo Cedeplar, Universidade Federal de Minas Gerais (UFMG). Consultora independente. E-mail: < vanessalcf94@gmail.com>.

"PhD em Sociologia pela University of Texas at Austin. Professora associada do Departamento de Demografia e pesquisadora do Centro de Planejamento e Desenvolvimento Regional, Universidade Federal de Minas Gerais (UFMG). E-mail: < paula@cedeplar.ufmg.br >.

"."Doutora em Demografia pelo Cedeplar, Universidade Federal de Minas Gerais (UFMG). Professora adjunta da Universidade de Brasília (UnB), campus Gama (FGA). E-mail: <mariliamfg@gmail.com>.
} 


\title{
FRONT DOOR OR EXIT DOOR? SCHOOL FAILURE IN HIGH SCHOOL ACCORDING TO STUDENTS AND SCHOOL COUNSELORS IN RIBEIRÃO DAS NEVES, MG
}

\begin{abstract}
The purpose of this article is to understand the motivations for school failure (infrequency, grade repetition and dropout) in the first year of high school and ways to reverse them. Data were collected in 2014, through focus groups with students of 15 to 19 years old and semi-structured interviews with counselors. School failure is due to work; family matters (no supervision of school activities; taking care of siblings, husbands, children); lack of money to pay for transportation; violence; lack of interest in classes; bad quality teachers; drug use; bad companies; bullying; and previous grade repetition. School failure could be reduced with actions by the State (better infrastructure, higher salaries, programs to keep teens at school), the school (motivated teachers, new ways of teaching, more dialogue between directors and students), the family (supervision of school activities, participation in parent-teacher meetings), and the student (more dedication, attention during class).

Keywords: School achievement. School failure. Dropout. High School. Teenagers.
\end{abstract}

\section{INTRODUÇÃO}

A partir da década de 90 do século passado, o Brasil iniciou a caminhada no processo da democratização da educação. Em 2000, a cobertura do Ensino Fundamental (EF) chegou a 97,0\% e, apesar de o Ensino Médio (EM) não ter atingido a universalização, a taxa de escolarização líquida (relação entre o número de matrículas na faixa etária adequada a determinado nível de ensino e a população na mesma faixa etária) teve uma expansão de $14,3 \%$, em 1980, para 32,6\%, em 2002 (CASTRO; TIEZZI, 2005). Em 2011, a taxa de escolarização líquida no EM atingiu 51,6\%, um avanço em relação à década anterior, mas ainda bem abaixo dos $72,4 \%$ verificados no EF. Soma-se a isso o fato de que, entre os grupos sociais, existe um enorme abismo. Em 2011, enquanto a taxa de escolarização líquida do EM era de 78,0\% para os mais ricos, era de apenas 32,0\% para os mais pobres (BRASIL, 2013).

O marco da discussão sobre o desempenho escolar foi o Relatório de Coleman et al. (1966), que apontou a importância do background familiar sobre as desigualdades de desempenho escolar entre os alunos norte-americanos. O desempenho escolar é um resultado multifatorial e pode ser analisado de várias formas, tais como baixa proficiência em disciplinas, distorção idade-série, reprovação, repetência, não frequência escolar, abandono escolar, evasão escolar, dentre outros.

O objetivo deste artigo é entender quais são as motivações para o fracasso escolar, medido através de infrequência, reprovação e abandono 
escolar na primeira série do Ensino Médio, a partir das visões de estudantes e coordenadores(as) de escolas pertencentes à rede estadual de ensino (REE) do município de Ribeirão das Neves (RN), MG. Os dados foram obtidos através de grupos focais com alunas e alunos e entrevistas em profundidade com coordenadoras e coordenadores, ambos realizados em escolas estaduais do município em julho de 2014.

A infrequência escolar se refere ao não comparecimento do aluno a $75 \%$ da carga horária anual total, de acordo com a Resolução 2.197 da Secretaria de Estado de Educação (SEE), enquanto a reprovação, relacionada ao rendimento do(a) aluno(a) em determinado ano, corresponde à situação na qual este(a) aluno(a), no fim do período letivo, obtém rendimento insuficiente para mudar de série, ficando impossibilitado de se matricular na etapa (série) seguinte no ano que se segue. Já o abandono escolar se refere ao movimento do(a) aluno(a) entre as séries e ocorre quando o(a) aluno(a) deixa de frequentar a escola antes de terminar o ano letivo, mas não se desliga formalmente desta através da transferência, fazendo com que, em sua matrícula, não haja informação sobre o rendimento escolar (BRASIL, 2010).

De modo geral, estudos realizados no Brasil sugerem que características individuais podem estar relacionadas ao desempenho escolar. Estudantes que são do sexo masculino (GUIMARÃES, 2010; RIANI; RIOS-NETO, 2008), que têm idade mais avançada (LEON; MENEZES-FILHO, 2002; RIANI; RIOS-NETO, 2008), que são pardos (FRANCESCHINI; MIRANDA-RIBEIRO; GOMES, 2016) ou pardos e pretos (ALVES; ORTIGÃO; FRANCO, 2007; GONÇALVES, 2008; GUIMARÃES, 2010), que trabalham (ALVES; ORTIGÃOO; FRANCO, 2007; GONÇALVES, 2008; LEON; MENEZES-FILHO, 2002), cujas mães ou os próprios estudantes não têm filiação religiosa (CUNHA, 2012) e, no caso das alunas, que são pardas (FRANCESCHINI; MIRANDARIBEIRO; GOMES, 2016) e têm filhos (ABREU; MIRANDARIBEIRO; CÉSAR, 2000), tendem a ter pior desempenho escolar.

Estudos quantitativos e qualitativos investigam a importância dos diversos aspectos dentro do universo da escola sobre o desempenho escolar. Estudo com professores, administrador e alunos, através de entrevistas semiestruturadas, revela a importância da forte liderança institucional (empoderamento, decisão de fazer compartilhada e desenvolvimento da capacidade humana), eficácia coletiva (eficácia dos professores, abertura para comunicação, trabalho em equipe, flexibilidade, aprendizado organizacional) e foco na instrução diferenciada para o aluno (adaptação do currículo, constante monitoramento e programas personalizados de orientação) como pontos importantes para se evitar o baixo desempenho escolar (AHUJA, 2007). 
Entrevistas em profundidade, comocomdiretores, supervisores, professores de Língua Portuguesa e Matemática, alunos da terceira série do EM e também a observação direta do ambiente escolar e das aulas de Matemática e Português, sugerem que a excelência institucional é atribuída mais às qualidades de seus alunos do que à prevalência da excelência na rotina da escola, nas suas estruturas pedagógicas e administrativas. Mesmo assim, foram apontados aspectos importantes relativos à escola que contribuem para o desempenho dos alunos, tais como firmeza, objetividade e clareza da direção; ambiente favorável ao ensino/aprendizagem; corpo docente experiente e comprometido com os resultados dos alunos; clima interno favorável às inter-relações e estabilidade do quadro de pessoal (RESENDE, 2005).

As características dos professores também são importantes no desempenho dos alunos, sobretudo aqueles que desenvolvem a prática reflexiva, conforme estudo que utiliza regressões múltiplas (AKBARI; ALLVAR, 2010). Outro estudo quantitativo, que utiliza modelos hierárquico e hierárquico espacial, investigou o ambiente escolar e observou que, quando as escolas possuem infraestrutura adequada, o efeito da escolaridade materna sobre a probabilidade de o aluno frequentar a escola na idade correta é reduzido. Desse modo, o efeito da educação materna sobre o desempenho escolar se reduz, o que possibilita a redução na desigualdade intergeracional (RIANI, 2005).

A ausência de rotatividade dos professores durante o ano letivo, a experiência média dos professores com mais de dois anos em sala de aula, o uso do computador pelo professor para fins pedagógicos e a conexão com a internet apresentaram um efeito positivo sobre o resultado médio obtido pelos alunos em Matemática (BIONDI; FELÍCIO, 2007). As instalações e os currículos das escolas apresentam menor efeito sobre a variação do desempenho do aluno, mas a qualidade dos professores tem uma forte relação com o desempenho deles e uma tendência de aumento nas séries mais avançadas (COLEMAN, 2008).

Dados para o Brasil e o estado de Minas Gerais indicam que o pior desempenho escolar durante o EM se dá na primeira série, em que são observados os maiores percentuais de reprovações, abandono escolar e distorção idade-série (quando o aluno cursa a série com idade acima da que seria correta). Em Ribeirão das Neves $(\mathrm{RN})$, município da Região Metropolitana de Belo Horizonte, a situação não é diferente. Em 2013, a taxa de reprovação na rede estadual de ensino no País como um todo foi de $17,6 \%$ na primeira série e $7,1 \%$ na terceira série. Se Minas Gerais ficou bem melhor que a média nacional, com $8,9 \%$ de reprovação na primeira série e $6,6 \%$ na terceira, $\mathrm{RN}$ ocupou a posição intermediária, com $13,7 \%$ de 
reprovação na primeira série e 5,8\% na terceira série. Já em relação às taxas de abandono escolar, 11,5\% dos alunos do Brasil como um todo abandonaram a escola na primeira série e $6,5 \%$ na terceira série, números bem próximos dos observados em Minas Gerais - 12,6\% e $6,0 \%$, respectivamente - e $\mathrm{RN}-12,5 \%$ e $6,8 \%$, respectivamente. Finalmente, a distorção idade-série na primeira série em RN $(35,2 \%)$ foi praticamente idêntica à de Minas $(35,8 \%)$ e ficou muito próxima à média nacional (36,5\%), ao passo que, na terceira série, ela foi menor em Minas $(22,4 \%)$ do que em RN (25,5\%), por sua vez menor que a do Brasil (28,9\%) (CENSO..., 2013). Os números indicam, portanto, que a primeira série do EM pode ser considerada a porta de saída da escola no EM, sugerindo a necessidade de investigar mais a fundo o porquê do baixo desempenho escolar e buscar alternativas para que essa série seja tão somente a porta de entrada do EM.

\section{RIBEIRÃO DAS NEVES: UM BREVE PANORAMA}

O município de Ribeirão das Neves (RN) está localizado na Região Metropolitana de Belo Horizonte, possui cerca de 155 mil quilômetros quadrados e tinha quase 300 mil habitantes em 2010. E caracterizado por uma forte homogeneidade social e por ser um território de pobreza e sem tradição industrial (ANDRADE; MENDONÇA, 2010). Apesar da redução no percentual de vulneráveis à pobreza nas últimas décadas passando de $71,2 \% \mathrm{em}$ 1991 para 53,6\% em 2000, em 2010 ainda havia cerca de 30,0\% dos habitantes do município nessa mesma condição (ATLAS..., 2013).

O crescimento populacional de RN foi marcado pela migração de uma população com baixa escolaridade. Em 2000, cerca de 68,0\% da população era composta por imigrantes, sendo que, no período de 1995-2000, quase 77,0\% deles possuíam, no máximo, 8 anos de estudo, o que contribui para a reprodução da pobreza das famílias (SOUZA, 2008). Em 2010, a maior parcela da população de RN ainda apresentava baixa escolaridade (quase 60,0\% com EF incompleto e cerca de 20,0\% com EM incompleto), uma pequena parcela tinha EM completo (em torno de $20,0 \%$ ) e uma ínfima proporção tinha Ensino Superior (ES) completo (cerca de 2,0\%). Entre a população com 18 anos ou mais, cerca 46,0\% havia completado o EF e $27,0 \%$ o EM, ao passo que, entre a população de 25 anos ou mais, ainda havia $8,0 \%$ de analfabetos. Esse cenário pode ser efeito da composição da população, em função do peso das gerações mais antigas com menos escolaridade, mas revela, sem sombra de dúvida, uma população que, além de ser pobre, também tem baixa escolaridade (ATLAS..., 2013). 
A baixa escolaridade da população de $\mathrm{RN}$ tem reflexos no rendimento mensal. Em 2010, quase 38,0\% das pessoas com 10 anos ou mais de idade não possuíam rendimento mensal e cerca de 30,0\% ganhavam menos de dois salários mínimos. Entre a população com idade de 18 anos ou mais que estava ocupada em 2013, 80,6\% recebiam até dois salários mínimos, 52,7\% tinham EF completo, 32,3\% tinham EM completo e somente 3,0\% haviam cursado ES (ATLAS..., 2013).

\section{METODOLOGIA E DADOS}

Para entender melhor quais são os motivos do fracasso escolar na perspectiva da infrequência, reprovação e abandono entre os adolescentes matriculados na primeira série do Ensino Médio, em 2014, em escolas da REE do município de RN, adotou-se a técnica de análise de Grupos Focais (GFs) com alunos e alunas, entrevistas em profundidade com coordenadoras e coordenadores. Em seguida, para análise das informações, aplicou-se a técnica da Análise de Conteúdo (AC). Todos os procedimentos realizados são descritos a seguir.

\section{A teoria}

A análise qualitativa é um instrumento que possibilita captar informações que não são possíveis através da análise quantitativa, aprofundando nas questões de interesse com base nas perspectivas dos participantes. Apesar de as pesquisas qualitativas produzirem dados confiáveis e válidos (FAZITO, 2009), seu uso na demografia é mais recente que em outras áreas das ciências sociais. Os trabalhos pioneiros foram realizados por Caldwell, que fez etnografias na África ainda na década de 1970, e Knodel, que, na década de 1980, conduziu grupos focais, os quais, combinados com dados quantitativos, ajudaram a compreender a queda da fecundidade na Tailândia.

No Brasil, a pesquisa qualitativa em demografia vem aos poucos ganhando espaço, uma vez que os demógrafos não se contentam só em saber "quantos", mas querem entender "como" e "por que" (MIRANDA-RIBEIRO; SIMÂO, 2013). Entre 2001 e 2011, a Revista Brasileira de Estudos Populacionais (REBEP), periódico mais importante para a demografia brasileira, publicou 190 artigos, dos quais apenas 20 se basearam em dados qualitativos e 5 combinaram dados quantitativos e qualitativos (MIRANDA-RIBEIRO; SIMÃO, 2012).

Entre as técnicas da pesquisa qualitativa estão os grupos focais (GFs), que tiveram início na metade da década de 80 do século passado (GATTI, 2005), aplicados em áreas relacionadas às pesquisas 
de mercado, política, estudos de comunicação, educação, ciência política e saúde pública (MORGAN, 1996). Ao utilizar a técnica de $\mathrm{GF}$, o interesse do pesquisador está não em saber o que as pessoas pensam e expressam, mas, sim, como elas pensam e por que pensam daquela forma (GATTI, 2005).

O GF é uma reunião entre pessoas que discutem sobre um tema levantado pelo pesquisador, sob a condução de um moderador, que tem o papel de fazer fluir a discussão sem se posicionar a respeito de questões levantadas. As informações emanadas desse tipo de discussão podem implicar aspectos normativos e valorativos do tema (FALLON; BROWN, 2002; GATTI, 2005; MORGAN, 1996), tornando-se, portanto, uma fonte de dados (MORGAN, 1996) e passíveis de ações políticas (FALLON; BROWN, 2002).

Alguns aspectos importantes devem ser levados em conta no momento de realização do GF. Os papéis do moderador e do relator devem ser informados ao grupo, assim como o fato de a discussão ser gravada, justificando a necessidade de não se perderem as informações. A confidencialidade das informações também deve ser enfatizada no início da realização do GF, de forma a garantir aos participantes o anonimato (MORGAN, 1996). Todas essas informações devem ser dadas quando da leitura do TCLE - Termo de Consentimento Livre e Esclarecido.

A seleção dos participantes dos GFs deve privilegiar características comuns entre os membros, que os qualifiquem para discussão do tema em questão, de modo que seja o mais homogêneo possível (FALLON; BROWN, 2002; GATTI, 2005; MORGAN, 1996). Há controvérsias a respeito da participação de pessoas que se conhecem, já que se prevê o anonimato, mas, muitas vezes, quando os participantes se conhecem, podem se sentir mais à vontade para se expressarem (FALLON; BROWN, 2002).

O número de grupos necessários e o ambiente no qual será realizado também devem ser levados em conta. Segundo Morgan (1996), grupos menores são indicados para temas que envolvem o emocional dos participantes e geram maior nível de participação dos mesmos, enquanto grupos maiores são apropriados para temas mais neutros, que demandam menor nível de envolvimento dos participantes. De acordo com Fallon e Brown (2002), o número de participantes deve ficar entre quatro e oito membros, sendo oito um número ótimo de participantes.

Outro método também utilizado na pesquisa qualitativa é a entrevista semiestruturada, que tem como característica teorias e hipóteses que são as bases para os questionamentos centrais feitos 
através de um roteiro com perguntas. Apesar dessa característica, esse tipo de entrevista possibilita que informações surjam de forma mais livre, de modo que as respostas não são padronizadas (MAZZINI, 2004). As diversas técnicas qualitativas podem ser empregadas conjuntamente, dependendo dos objetivos dos pesquisadores.

As informações obtidas nas diversas técnicas qualitativas podem ser analisadas através da análise de conteúdo. Essa técnica surgiu no século $\mathrm{XX}$, nos Estados Unidos, aplicada à interpretação de material jornalístico. A partir de 1960, passou a ser utilizada também em outras áreas das ciências humanas (CAREGNATO; MUT'TI, 2006). Ela constitui um conjunto de procedimentos e técnicas para extrair sentido dos textos por meio de unidades de análises (SILVA; GOBBI; SIMÃO, 2005).

\section{A prática}

A população-alvo desta pesquisa foram os alunos da primeira série do EM, matriculados em escolas da REE, com idades entre 15 e 19 anos. As escolas escolhidas para a realização dos GFs e das entrevistas estavam entre as participantes da Pesquisa de Avaliação do Ensino Médio - Pesquisa Jovem, um survey de cunho longitudinal, realizado entre 2007 e 2010 pelo Centro de Desenvolvimento e Planejamento Regional (CEDEPLAR) da Faculdade de Ciências Econômicas (FACE), Universidade Federal de Minas Gerais (UFMG), com a colaboração da Secretaria de Estado de Educação (SEE) e o financiamento da Secretaria de Desenvolvimento Social (SEDESE) e da Fundação de Amparo à Pesquisa do Estado de Minas Gerais (Fapemig).

Das escolas estaduais do município de $\mathrm{RN}$, onze fizeram parte da Pesquisa Jovem. A amostragem dessas escolas foi feita porconglomerados em um estágio, com estratificação geográfica. O número de escolas em cada um dos estratos geográficos foi proporcional ao número de escolas que pertenciam a cada uma das regiões (Amostragem Sequencial de Poisson) igual ao número de alunos matriculados na primeira série do EM. Para selecionar as escolas, foi utilizada a amostragem proporcional ao tamanho da escola (VIEIRA, 2009).

A pesquisa qualitativa utilizada no presente trabalho, intitulada Conciliando trabalho e escola? Licões de uma coorte de alunos do $1^{\circ}$ ano do Ensino Médio da Rede Estadual de Ensino do município de Ribeirão das Neves, foi realizada em 2014, com a aprovação Comitê de Ética e Pesquisa (COEP) da UFMG (Parecer Consubstanciado 198.526). A coleta de dados foi autorizada pela Secretaria de Estado de Educação de Minas Gerais Subsecretaria de Desenvolvimento da Educação Básica, Comissão de Ética. Não houve conflito de interesse em relação aos métodos utilizados como parte da investigação ou interesse financeiro dos pesquisadores. 
Foram visitadas três escolas nas regiões de Justinópolis e Centro de $\mathrm{RN}$, onde foram realizados oito GFs, com oito participantes em cada um. Quatro grupos eram compostos somente por alunas, e quatro, somente por alunos. Os GFs foram previamente agendados através de contato telefônico feito entre a primeira autora e a coordenação das escolas (diretores, supervisores ou coordenadores) e conduzidos em horário de aula, no período entre 16 e 25 de julho de $2014^{1}$, utilizando um roteiro já testado previamente.

Durante a realização do primeiro GF, percebeu-se a necessidade de ouvir, também, a direção da escola a respeito dos aspectos discutidos nos grupos. Era preciso entender o outro lado das estórias. Diante disso, foram realizadas entrevistas semiestruturadas com coordenadores e coordenadoras nessas escolas. A partir das transcrições, a análise dos dados foi realizada com base na técnica de AC.

O material foi transcrito, lido, grifado e codificado, considerando primeiramente os grandes temas e, em cada um deles, os respectivos subtemas. Também foi feita a identificação de cada fala, usando a codificação para todos os participantes, sempre indicados pela letra $\mathrm{P}$, seguindo a posição que este ocupava na mesa do GF. A numeração foi feita em sequência com relação aos grupos, gerando 64 códigos (8 participantes x 8 grupos) para as falas (P1 a P64). Infelizmente, não foi possível identificar absolutamente todas as falas porque, em alguns momentos, os alunos e as alunas falavam ao mesmo tempo. Para não perder o conteúdo destas, lançou-se mão da codificação utilizando P?, sendo $\mathrm{P}$ o código para participante, $\mathrm{e}$ ?, aquele(a) cuja fala não foi identificada. Quando um nome que não correspondia a nenhum dos integrantes do GF era mencionado, foi utilizada a sua inicial. Para os coordenadores e as coordenadoras, a codificação utilizada foi a letra $\mathrm{C}$, seguida de um número, que seguiu a ordem das entrevistas. $\mathrm{Na}$ escola 1 , foram entrevistados os coordenadores do turno da manhã (C1) e o do turno da noite (C2). $\mathrm{Na}$ escola 2, somente o(a) coordenador(a) do turno da manhã (C3) foi entrevistado(a). O mesmo ocorreu na escola 3 (C4). As falas da moderadora foram identificadas pela letra $\mathrm{M}$. Os trechos com as falas dos grupos estão identificados através da letra $G$ e dos números de 1 a 8 , que correspondem aos 8 grupos realizados.

\section{OS RESULTADOS}

Após todos os procedimentos realizados conforme descrito na seção anterior, foi possível obter alguns resultados que são apresentados a seguir. Eles estão divididos conforme as visões de 
alunos(as) e coordenadores(as) a respeito das motivações para a infrequência, a reprovação e o abandono escolar e quais são as formas de reverter o fracasso escolar.

\section{Motivações para infrequência, reprovação e abandono escolar: o que dizem os(as) alunos(as) e os(as) coordenadores(as) das escolas?}

O trabalho é apontado por estudantes e coordenadores(as) como um dos motivos da infrequência. A literatura aponta que o trabalho ocorre, em maior medida, entre os alunos homens (ALVES; ORTIGÃO; FRANCO, 2007; GONÇALVES, 2008; LEON; MENEZES-FILHO, 2002). Segundo a fala de um coordenador, é exatamente isso que ocorre na escola em RN: trabalhar é mais comum entre os rapazes, muitos deles arrimos de família, responsáveis pelo sustento da casa. Mais vale o retorno imediato do trabalho, muito valorizado e necessário para a família, do que a possibilidade de um emprego melhor no futuro, em função de uma maior escolaridade. São exatamente os rapazes os mais afetados pelo baixo desempenho escolar, se comparados às alunas (GUIMARÃES, 2010; RIANI; RIOS-NETO, 2008). Há dificuldade em conciliar trabalho e estudo, conforme a fala de um participante de grupo focal, que se refere ao cansaço depois de um dia inteiro de serviço.

M: E como é que é a frequência dos meninos aqui na escola? Faltam muito?
C2: Faltam. A gente tem um problema no regular [...]. A gente tem problemas de
infrequência com os meninos. A questão do trabalho acaba sempre influenciando, às vezes
por necessidade mesmo. Ás vezes por aquela coisa dele começar a trabalhar e ganhar um
dinheiro, de repente; [...] O trabalho acaba afetando os dois, mas os meninos muito mais,
às vezes por ser o arrimo de família ou alguma coisa nesse sentido [...]. As meninas, às
vezes, deixam de vir por conta do trabalho, mas ainda sim é bem menor que a dos meninos.
Às vezes um descaso com o estudo, a falta de interesse mesmo. A questão familiar também
eu acho que faz. muita diferença. M: Quais são os motivos que vocês acham que o aluno tem para faltar à aula?

P29: Depende. Talvez cansado do serviço [...] às vezes a pessoa trabalha e fica cansada. [...] (G4)

Outros aspectos que acabam interferindo na frequência escolar e/ou na continuidade dos estudos estão relacionados a questões familiares. Uma delas é o acompanhamento dos estudos. Apesar de os alunos já estarem no EM, os alunos e as alunas que não têm acompanhamento da família acabam tendo pior desempenho, chegando à reprovação. 
M: E no seu ver, com relação à família, você acha que tem diferenciação em termos da família do aluno que é reprovado, a característica desse aluno?

C2: Porque, na verdade, eu ainda sim acredito que aquelas familias que não acompanham, que não são um suporte ali, a incidência dos meninos reprovados ainda é maior, mas também acontece de famílias que dão um suporte, que dão estrutura e não obtém a resposta. Ainda assim, no geral, os alunos que são reprovados são aqueles alunos que de repente têm uma estrutura familiar mais frágil.

Muitas vezes, a mãe precisa trabalhar e o adolescente acaba tendo a responsabilidade de cuidar dos irmãos, prejudicando seus estudos por não poder comparecer às aulas. Alunas casadas também têm tarefas domésticas, o que pode prejudicar a frequência à escola.

M: E quais são os motivos que levam o aluno a faltar aula?

P58: [...] E a maioria das pessoas faltam por causa de irmão, a mãe vai trabalhar e fica olhando o irmão. Tem uma menina na minha sala, duas, uma olha o irmão para a mãe trabalhar e a outra trabalha e mora com o marido também, então não vem à aula. (G8)

Quando ocorre uma gravidez na adolescência, o que primeiro vêm à mente é que as jovens mães abandonam a escola. No entanto, há exemplos na literatura de situações de apoio das famílias às mães adolescentes através do cuidado dos bebês, o que permite às mães adolescentes continuarem na escola (ABREU; MIRANDARIBEIRO; CÉSAR, 2000; BRANDÃO; HEILBORN, 2006). Além disso, o nascimento de um bebê pode incentivar a mãe a querer concluir seus estudos, a fim de garantir um futuro melhor para seu filho (MIRANDA-RIBEIRO, 2012). Os GFs e as entrevistas indicam que a gravidez é causa de infrequência e reprovação e, em menor medida, de abandono. O papel das avós dos bebês (mães das adolescentes) é fundamental para que estas permaneçam na escola.

$\mathrm{M}: \mathrm{E}$ as meninas, quais são os motivos que elas abandonam?

P54: Gravider:

$\mathrm{M}$ : A maioria abandonava ou tinha algumas que continuavam?

P56: Algumas voltavam depois da gravide:

M: E as que voltavam, como elas continuavam a estudar? Como que elas conseguiam? Como é que ficava o filho?

P?: Ficava com a parentada dela.

P54: Com a mãe dela. (G7)

M: Quais são os motivos que você acha que são maiores para reprovação aqui?

C2: Primeiro, infrequência, essa questão que eu não sei nem como falar especificamente o que que é, que eles vêm para escola, não valorizam o estudo, chega no final e querem correr atrás. [...] A menina às vežes engravidou, processo de licença maternidade, algum menino 
que se posicionou na questão do trabalho, estava trabalbando e não deu, mas a gente viu que esteve ai e procurou esforçar em alguma coisa. [...]

M: Você tem observado se essas que tem engravidado, elas têm tentado se manter na escola?

C2: Tem. Elas vêm até o momento que elas conseguem vir, depois saem e retornam. Até que elas não estão evadindo pós-gravidežnão. Acho que o pai ajuda, a mãe ajuda e elas crescem.

Outra dificuldade vivida por muitos adolescentes de $\mathrm{RN}$ é a dificuldade de custear a ida e a volta da escola. Não ter dinheiro para o transporte (ônibus convencional ou van escolar) contribui para que os estudantes de menor poder aquisitivo sejam infrequentes.

P62: Quem morasse longe, tipo, desse um cartão para a gente poder pegar o ônibus.

P58: Por isso que a gente falta. Você viu como é que a escola está vą̦ia? (G8)

C4: Desses 85 [estudantes] que eu falei para você, eu tenho uns cinco nessa situação. Eu tenho aluno que falta por causa de transporte, porque nem todo dia ele tem condições de pagar o transporte, não tem condições de pagar o especial.

Assim como em muitas cidades brasileiras, a violência é um problema grave em $\mathrm{RN}$ e acaba sendo um dos motivos para não ir à aula. Cunha (2012), ao analisar a relação entre religião e desempenho escolar em alguns municípios de Minas Gerais, incluindo RN, indica que mais de $50 \%$ dos adolescentes percebe a vizinhança da escola como violenta. As falas dos alunos e das alunas de RN reforçam a ideia de que a violência, tanto dentro quanto fora da escola, contribui para infrequência.

M: E vocês acham essa violência interfere alguma coisa no aluno aqui dentro da escola?

P47: Interfere muito.

P48: A pessoa vai ficar com medo de vir à escola porque ameaşou ele, falou assim: "Vou te pegar na saída".

P46: Às vezes pode estar tendo guerra ali, lá, ai aqui acabam as aulas.

P48: Muitas pessoas que moram lá embaixo podem estar dando tiroteio, aí muitos ficam com medo de sair porque pode morrer de bala perdida [...] (G6)

A falta de interesse do próprio aluno é outro fator que interfere no desempenho, contribuindo para a infrequência escolar, que, por sua vez, pode levar à reprovação, tanto pelo número de faltas quanto pela perda de conteúdo. O problema da falta de interesse é que, muitas vezes, mesmo que a escola tenha uma postura de viabilizar a recuperação dos alunos para que possam progredir de série, isso não acontece.

M: E quais são os motivos que vocês acham que leva um aluno a ser reprovado?

P32: É muito dificil ser reprovado. 
P29: Porque os professores que ajudam muito.

P28: Ficam insistindo, dando trabalho, atividade com ponto.

P29: [...] Eu mesma, ano passado, eu tomei bomba mais por conta disso, eu faltava muito, eu ficava muito cansada e en preferia dormir do que ir pra escola. Teve bagunça também. Eu não fazia nada na escola, en ia na escola só para conversar, sópara zoar. Tenho vários motivos. (G4)

M: Quais são as rą̃ôes para tomar bomba?

P11: Não estudar, não prestar atenção na aula.

P9: Falta.

P?: Eu tomei bomba por causa de falta, matar aula. (G2)

A motivação e o empenho dos alunos para estudar estão muito relacionados à figura do professor (FRANCHIN; BARRETO, 2006; PONTES et al., 2008; PORTO, 2005; RIBEIRO et al., 2004). A partir do momento em que o professor ou a professora não estabelece uma relação de empatia, isso acaba por prejudicar o andamento da aula e a produtividade da turma.

M: Me fala, quais são os motivos que um aluno tem para faltar à aula?

P23: Aulas ruins.

P21: Preguiça.

P22: Professor chato.

P19: Alunos folgados. (G3)

M: Qual outro motivo que vocês acham da reprovação?

P39: Ah, tem vez, que o aluno não aguenta o professor e acaba discutindo com o professor. Depois disso aí o professor comeca a pegar no pé, tipo, vai fazendo as coisas para reprovar o aluno.

P37: Professor que não passa atividade e só fica falando. Que nem o professor lá de Geografia, só fala, fala e fala, no final dá prova e ninguém sabe. (G5)

Somam à lista das razões para o abandono escolar as drogas, as más companhias, a experiência de já ter sido reprovado, o bullying e a falta da presença familiar.

M: E os motivos para abandonar a escola, quais vocês acham que poderiam ser?

P?: Vicio.

P?: Drogas.

P8: Falta de interesse.

P?: Não conseguem entender a matéria, acham muito difícil e resolvem desistir de vez:

P?: Eu não acho isso não. Acho que é más influências. (G1) 
M: E para abandonar a escola, quais são os motivos eu vocês acham?

P34: Tomar duas bombas.

P40: Desanima.

P39: Comeşa a desanimar. Porque 'vai' vindo aí os alunos pequenos e vai ficar na sala deles?

P40: Ai os meninos sofrem bullying e falam que é nós. (G5)

Em suma, os motivos para a infrequência, a reprovação e o abandono escolar apontados por estudantes e coordenadores(as) da $1^{a}$ série do EM em RN são bastante similares e se reforçam. São eles o trabalho, as questões familiares (falta de acompanhamento escolar por parte das famílias, necessidade de cuidar de irmãos, maridos e filhos), não ter dinheiro para o transporte escolar, a violência na escola e fora dela, a falta de interesse nas aulas, os professores ruins, o uso de drogas, as más companhias, o bullying e ter tido reprovação anterior.

Quais são as formas de reverter essa situação? Esse é o tema tratado a seguir.

\section{Como reverter o fracasso escolar? $\mathrm{O}$ que dizem os(as) alunos(as) e os(as) coordenadores(as) das escolas}

As opiniões dos participantes dos grupos focais e das coordenações das escolas a respeito das medidas que poderiam ser tomadas para mudar o quadro de infrequência, reprovação e abandono escolar foram muito similares e passam por ações do Estado, da escola, da família e do próprio aluno.

$\mathrm{Na}$ esfera do Estado, percebe-se a necessidade de iniciativas do governo que possam motivar os alunos a completarem seu ciclo escolar, tais como o programa Poupança Jovem, bem como uma ação direta dentro das escolas, através do acompanhamento diário do que acontece com os adolescentes, como forma de intervenção mais rápida sobre os problemas. Além disso, é preciso haver investimento nas escolas e nos professores, sobretudo em termos salariais. Um professor que trabalha em várias escolas e/ou em três turnos não tem condições de preparar suas aulas a contento.

\footnotetext{
M: Acabar com a bomba. Ninguém mais vai tomar bomba, nós vamos fazer um Programa que faça com que os alunos tenham um bom desempenho. Então o que que gente vai faz̧er? P?: Acho que já tem o Poupança Jovem. (G1)

C2: Um projeto de acompanhamento de um profissional especifico para acompanbar isso. No dia a dia, ou [...] estar acompanhando ele e observando quais são os problemas. [...] Não estou falando só da questão da nota, mas o resgate dos problemas que ele vem sofrendo, a avalanche de coisas que acontecem na vida dele nesse perído de pré-adolescência, adolescência. [...].
} 
C3: Reprovação, maior empenho do Estado, mais verba, mais comprometimento, escolas mais planejadas, um monte de coisas.

M: E em termos dos professores, você acha que deveria ter alguma mudança? Como é que seria isso?

C3: Na realidade, e isso aqui é opinião pessoal [...]. O salário é tão baixo que eles trabalham dois, três turnos. Eu tenho professor que trabalha em quatro escolas. Como é que você faz? Me explica como que o professor entra na sala, qual tempo que ele vai arrumar para planejar uma aula $[. .$.$] ?$

No que tange ao papel da escola no desempenho escolar dos alunos, alguns trabalhos apontam que o efeito da escola é menor, se comparado ao background familiar (RIANI, 2005) ou à qualidade dos seus alunos (RESENDE, 2005; RIANI, 2005). Mesmo assim, é notória a sua importância, seja nos aspectos ligados à infraestrutura e aos currículos (COLEMAN, 2008), seja com relação às características de seus professores (AKBAR; ALLVAR, 2010) ou à capacidade institucional no que diz respeito à gestão (AHUJA, 2007; RESENDE, 2005).

Nesse sentido, a gestão escolar, que também aparece na forma de como a escola estabelece a relação com os alunos, é um diferencial importante. Resende (2005) e Ahuja (2007), em seus estudos voltados para EM, verificaram a importância da liderança institucional que abrange a firmeza, a objetividade e a clareza da direção como fatores primordiais para o bom desempenho do aluno. Já os participantes dos GFs mencionam, além da firmeza, a importância da escuta por parte da diretoria da escola.

M: Gente, o que vocês acham quais são os motivos para o sucesso escolar, ter um bom desempenho escolar?

P20: Diretoria escutar mais o aluno.

P22: Disciplina.

P18: Ser mais severa. (G3)

Segundo a literatura, o papel dos professores em sala de aula é decisivo no processo de aprendizagem (AKBARI; ALLVAR, 2010; COLEMAN, 2008; FRANCHIN; BARRETO, 2006; PONTES et al., 2008; PORTO, 2005; RIBEIRO; FONSECA; SILVA, 2004). Em $\mathrm{RN}$, alunos e alunas querem aulas mais dinâmicas e interativas, com a utilização não somente do quadro negro, mas também com vídeos, aulas em salas de informática e disponibilidade de material didático para todos os alunos. O acompanhamento das aulas através da mera cópia do que o professor escreve no quadro é monótona, cansativa e, na opinião de alunos e alunas, pouco eficaz.

$\mathrm{M}:[\ldots]$ E o professor, como ele deveria ser?

P54: Os professores têm que ter paciência. 
P56: Ter aulas mais interativas, mais divertidas.

P56: Menos escrita e mais prática.

P52: Mais informática.

P54: Nós 'aprenderia' melhor se fosse do jeito que nós 'está' aqui [conversando, em círculo]. Nós 'aprenderia' mais se fosse desse jeito aqui que copiando. Copiando nós não 'aprende' nada não.

P56: Se já mudasse basicamente igual a gente está falando, os alunos todos seriam interessados mais na escola. (G7)

M: Então vocês me falaram o motivo para poder ter um sucesso bacana na escola [...]. Tem mais alguma coisa que faz o aluno ter um bom desempenho escolar?

P58: Se tivesse material direito, né? Porque livro é emprestado. Eles vêm aqui e pegam o livro, você tem 50 minutos para copiar o que você quer. [...] Quando os professores passam filme relacionado à matéria, História mesmo, que fala dos caras lá... (G8)

É importante lembrar que o professor criativo pode promover aulas dinâmicas e interativas, mas a escola, através de sua infraestrutura, precisa ser uma aliada. Nesse aspecto, é necessária uma atenção maior tanto na qualidade quanto na forma de utilização dos recursos existentes nas escolas, uma vez que estudos apontam que as escolas, a partir de suas instalações, currículos e, principalmente, da qualidade dos professores interferem sobre o desempenho de seus alunos (COLEMAN, 2008).

Outra questão relevante é pensar que, além da necessidade de o Estado garantir que as escolas tenham infraestrutura adequada, os professores precisam ser capacitados para utilizar os meios oferecidos, bem como que a escola seja capaz de manter o espaço conservado e em atividade. Um dos espaços muito desejados pelos adolescentes é a sala de informática, que, em algumas escolas, é subutilizada, ocupada para outra função ou não tem todos os equipamentos necessários.

P37: A quadra tem buraco uns buracos desse tamanho assim.

P39: A sala de vídeo acabou.

M: Porque que acabou?

P36: Porque agora é sala normal.

M: Biblioteca, vocês gostam da biblioteca.

P40: Tem a sala de informática, mas lá não tem mouse. (G5)

P54: Podia ter sala para informática. Tinha uns computadores aqui, mas nem tem mais.

M: Laboratório tem?

P?: Tem, mas nós não 'usa'. Pelo menos eu não uso. (G7)

M: De infraestrutura, você acha que teria alguma coisa que poderia melhorar? 
C4: A questão mesmo da adequação dessa tecnologia que eu estou falando.

M: Então seria ter a sala de informática? Vocês têm sala de informática aqui?

C4: Tem, mas eu nem sei quantos computadores tem funcionando. A professora de Tecnologia da Informação, ela já foi lá, já olhou, e ela falou: "C4, eu tenho condicõos de atender, acho que quatro meninos ou cinco de cada vez". É pouco.

Para diversificar e dinamizar a produção do conhecimento, atividades como excursões e palestras podem ser uma forma mais prazerosa de aprendizado. Essas são atividades muito desejadas por alunas e alunos. No entanto, como se trata de uma população de alta vulnerabilidade, seria necessário que elas fossem custeadas pelo Estado.

M: O que mais teria que ter nessa escola?

P64: Palestras.

M: Palestras sobre o quê?

P58: Gravidez, gente. Está precisando de incentivo aí.

P?: O mercado de trabalho também podia ter.

P60: Excursões. Eu acho que deveria ter muitas excursões.

P61: O Governo devia cobrir também porque é caro. Eu não tenho condição de ficar pagando caro não. (G8)

P30: Ter coisas novas na escola para ter mais interesse. Tipo, uma excursão para incentivar a gente a estudar; usar a sala de informática; [...]. Ter coisas diferentes nas aulas, porque só ficar escrevendo texto no quadro e explicando também...(G4)

M: E se você fosse fazer um programa que você fosse eliminar o baixo desempenho, não vou falar bomba porque no caso do Estado evita-se o máximo ter bomba, o que você faria?

C3: Escola Integral. [...] Porque, quando você faz. uma coisa diferente com eles, quando você sai para uma excursão com eles, [...] dentro da escola, ou um sarau, uma festa, uma feira de cultura, eles adoram. Uma aula diferenciada eles adoram.

Para reverter o quadro que leva os(as) alunos(as) à infrequência, à reprovação e ao abandono escolar, são necessárias, também, ações das famílias e dos próprios alunos. Apesar de o EM ser uma fase do ciclo de escolarização na qual o acompanhamento escolar pelos pais surte menores efeitos quando comparado ao EF (MARE, 1980), a educação iniciada no seio familiar desde a primeira infância, através de apoio, incentivo, cobrança e participação em reuniões, ainda é importante. Quando priorizada na fase escolar inicial, os resultados tendem a permanecer nos ciclos futuros. Segundo vários estudos, o acompanhamento da vida escolar dos filhos tem papel importante no desempenho escolar dos filhos (COLEMAN, 1988; HOANG, 2007).

M: E o que que vocês acham que uma familia pode ajudar para ter um estímulo maiorpara o seu filho ter sucesso escolar? 
P7: Educar desde pequeno. Agora eu acho que não adianta mais não.

P8: Não deixar jogado.

P?: Tem que estar participando da vida escolar do filho.

P5: Eu acho que conversar bastante com o filho. Isso ajuda bastante. Meus pais conversam.

P3: Ela faz muita reunião, só que os que precisam mesmo vir não vem. (G1)

M: E o quê que precisa para ser um bom aluno?

P15: Dedicação. Muita dedicação.

P13: Calar a boca dentro de sala e prestar atenção. (G2)

M: E tem relação à presença dos pais com os alunos que são mais produtivos ou não?

C2: [...] Vamos usar um termômetro, a reunião de pais. [...] os pais que estão na reunião são dos alunos bons. Aqueles que realmente a gente precisa que venham para a gente conversar, para a gente pontuar alguma coisa, eles acabam não vindo. Só vem quando solicitado, quando o filho acaba sendo reprovado ou alguma situação específica na escola.

Em suma, as vozes de estudantes e coordenadores(as) do $1^{\circ}$ ano do EM em $\mathrm{RN}$ sugerem que algumas ações poderiam reduzir ou até mesmo reverter o fracasso escolar. São elas ações do Estado (infraestrutura nas escolas, salários de professores decentes, programas de incentivo à permanência na escola), da escola (professores mais bem-preparados e motivados, novas práticas de ensino, que vão além da aula expositiva, escuta dos problemas por parte da diretoria), da família (acompanhamento do desempenho escolar e maior participação em reuniões na escola) e do próprio aluno (mais dedicação e atenção em sala de aula).

\section{CONSIDERAÇ̃̃ES FINAIS}

Os problemas relacionados ao desempenho escolar vêm sendo abordados na literatura, em grande medida, através de metodologias quantitativas, em estudos que têm privilegiado, sobretudo, o Ensino Fundamental. Este artigo utilizou dados qualitativos para analisar outra fase escolar, qual seja, o Ensino Médio, o maior gargalo na educação brasileira atualmente. Com o objetivo de entender, de acordo com estudantes e coordenadores(as) de escolas da rede estadual do município do Ribeirão das Neves, MG, quais seriam as motivações para o fracasso escolar - entendido como infrequência, reprovação e abandono - e quais seriam os meios para revertê-lo, foram realizados oito grupos focais com os adolescentes e quatro entrevistas semiestruturadas com as coordenações. A análise dos dados foi feita através da técnica de análise de conteúdo. 
Em municípios de alta vulnerabilidade social, como é o caso de $\mathrm{RN}$, os problemas relacionados a infrequência, reprovação e abandono escolar são ainda mais preocupantes. Cabe lembrar que, no que tange à $1^{\text {a }}$ série do EM, o município tem elevadas taxas de reprovação (13,7\%) e abandono (12,5\%) (CENSO..., 2013). Nesse sentido, os participantes dos GFs se constituem em um grupo bastante seletivo, pois permaneceram na escola até a $1^{a}$ série do EM. Os mais vulneráveis já evadiram antes disso.

De modo geral, as percepções dos estudantes e das coordenações a respeito das motivações para os três tipos de fracasso escolar foram similares. As adolescentes do sexo feminino são, em grande medida, as responsáveis pelo cuidado de irmãos (em substituição às mães, que estão trabalhando), maridos (entre as unidas) e filhos (no caso das que são mães), assumindo o papel de cuidadoras. Em algumas situações de gravidez, a continuidade dos estudos somente é possível com a ajuda das famílias, sobretudo das avós. Já os adolescentes do sexo masculino, muitas vezes, são os responsáveis pelo sustento da família, assumindo o papel de provedores. Ambos os papéis de gênero, apesar de extremamente tradicionais, têm um impacto negativo no desempenho escolar, levando a um aumento da infrequência, da repetência e do abandono.

Mesmo que o acompanhamento da vida escolar dos alunos pelos pais tenha maior peso no EF, a percepção tanto dos adolescentes quanto das coordenações é que ele ainda se faz necessário no EM. Foram mencionados acompanhamentos diários, através de monitoramentos, cobranças e incentivos, além de participação em reuniões nas escolas. É importante salientar que esse acompanhamento foi reconhecido pelos entrevistados como uma das maneiras de se reduzir o fracasso escolar.

A falta de interesse por parte de alunos e alunas é assustadora, mas, ao mesmo tempo, perfeitamente compreensível. Impossível ter estudantes interessados em aulas cansativas, com muita cópia de matéria passada no quadro, com pouca interação entre professor(a) e alunos. Ao mesmo tempo, é impossível ter professores motivados se os salários são baixos, e a carga de trabalho deles, absurdamente alta. Soma-se a isso a falta de infraestrutura das escolas - salas de informática equipadas e em perfeito funcionamento, com professores treinados para utilizá-las; bibliotecas que sejam mais do que meros depósitos de livros; laboratórios para experimentos; excursões. Para resolver a falta de interesse dos alunos, é preciso que eles mesmos façam a sua parte prestando mais atenção às aulas e se dedicando mais aos estudos. Os professores também precisam fazer a parte deles ministrando aulas mais dinâmicas e criativas. Os diretores também precisam estar mais atentos às reclamações e às dificuldades dos alunos. No entanto, 
tudo isso depende, antes de mais nada, de o Estado fazer a sua parte, melhorando a infraestrutura das escolas, oferecendo treinamento aos seus funcionários e pagando salários justos.

A violência também entra no rol dos problemas que merecem mais atenção, tanto dentro quanto fora das escolas, sobretudo em regiões de maior vulnerabilidade social, como é o caso de RN. Finalmente, entre as motivações para o fracasso escolar mencionadas pelos entrevistados e pouco usual nas abordagens sobre o tema está a dificuldade do custeio do transporte. Sem a garantia do direito de ir e vir dos alunos entre suas residências e a escola, aqueles de menor nível socioeconômico ficam ainda mais vulneráveis ao fracasso escolar.

A $1^{a}$ série é a porta de entrada do EM. No entanto, em RN, município de baixa renda e alto fracasso escolar (um a cada oito estudantes abandona a escola e cerca de um a cada sete repete a $1^{a}$ série), assim como tantos outros municípios pobres deste País, os muitos problemas que foram apontados por estudantes e coordenadores(as) podem transformar a porta de entrada em porta de saída.

\section{REFERÊNCIAS}

ABREU, D. M. X.; MIRANDA-RIBEIRO, P.; CÉSAR, C. C. "A gente na adolescência acha que sabe tudo mas não sabe nada": gravidez na adolescência, redes familiares e condições de vida das jovens mães e de seus filhos em Belo Horizonte. In: ENCONTRO NACIONAL DE ESTUDOS POPULACIONAIS, 12., 2000, Caxambu. Anais... Associação Brasileira de Estudos Populacionais (ABEP), 2000. v. 1.

AHUJA, R. Towards an Understanding of Excellence in Urban Pedagogy: A Portrait of a High School. Qualitative Report, v. 12, n. 1, p. 1-19, 2007. Disponível em: < http://www. eric.ed.gov/PDFS/EJ800156.pdf>. Acesso em: 14 mar. 2011.

AKBARI, R.; ALLVAR, N. K. Teacher Characteristics as Predictors of Students' Academic Achievement. TESL-EJ, v. 13, n. 4, 2010. Disponível em: < http://www.eric.ed.gov/PDFS/ EJ898204.pdf>. Acesso em: 14 mar. 2011.

ALVES, F; ORTIGÃO, I.; FRANCO, C. Origem social e risco de repetência: interação raça-capital econômico. Cad. Pesquisa, São Paulo, v. 37, n. 130, p. 161-180, jan./abr. 2007.

ANDRADE, L. T.; MENDONÇA, J. G. de. Explorando as consequências da segregação metropolitana em dois contextos socioespaciais. Cad. Metrop., São Paulo, v. 12, p. 169-188, jan./jun. 2010.

ATLAS do Desenvolvimento Humano no Brasil, 2013. Perfil do município de Ribeirão das Neves, MG. Disponível em: < http://atlasbrasil.org.br/2013/pt/perfil_print/ribeirao-dasneves_mg >. Acesso em: 27 mar. 2014.

BIONDI R. L.; FELÍCIO, F. Atributos escolares e o desempenho dos estudantes: uma análise em painel dos dados do Saeb. Brasília, DF: Instituto Nacional de Estudos e Pesquisas Educacionais Anísio Teixeira, 2007. Disponível em: <http://www.oei.es/pdfs/atributos_ escolares_desempeno_brasil.pdf $>$. Acesso em: 6 jan. 2011.

BRANDÃO, E. R.; HEILBORN, M. L. Sexualidade e gravidez na adolescência entre os jovens de camadas médias do Rio de Janeiro, Brasil. Caderno de saúde pública, Rio de 
Janeiro, v. 22, n. 7, p. 1421-1430, jul. 2006. Disponível em: <http://www.scielo.br/pdf/csp/ v22n7/07.pdf>. Acesso em: 11 ago. 2009.

BRASIL. Ministério da Educação. Taxa de distorção idade-série, por dependência administrativa e localização, nos níveis de Ensino Fundamental de 8 e 9 anos e Médio, segundo a região geográfica, unidades da federação e seus respectivos municípios. Brasilia: Instituto Nacional de Estudos e Pesquisas Educacionais Anísio Teixeira (MEC/INEP/DEED/CSI), 2013. Disponível em: <http://portal.inep.gov.br/indicadores-educacionais>. Acesso em: 18 nov. 2014.

CAREGNATO, R. C. A.; MUTTI, R. Pesquisa qualitativa: análise de discurso versus análise de conteúdo. Texto Contexto Enferm, Florianópolis, v. 15, n. 4, p. 679-84, out./dez. 2006. Disponível em: <http://www.scielo.br/pdf/tce/v15n4/v15n4a17>. Acesso em: 23 maio 2010.

CASTRO, M. H. G.; TIEZZI, S. A reforma do Ensino Médio e a implantação do Enem no Brasil: os desafios da educação no Brasil. 2005. Disponível em: <http://www. schwartzman.org.br/simon/desafios/4ensinomedio.pdf>. Acesso em: 29 jun. 2009.

CENSO da Educação Básica, 2013. Disponível em: < http://portal.inep.gov.br/basicacenso-escolar-sinopse-sinopse>. Acesso em: 6 mar. 2013.

COLEMAN, J. S. Social capital in the creation of human capital. Supplement: organizations and institutions: sociological and economic approaches to the analysis of social structure. American Journal of Sociology, Chicago, v. 94, p. 95-120, 1988.

COLEMAN, J. S. Desempenho nas escolas públicas. In: BROOKE, N.; SOARES, J. F. Pesquisa em eficácia escolar: origens e trajetórias. Belo Horizonte: UFMG, 2008. p. 26-32.

COLEMAN, J. S. et al. Equality of educational opportunity. Washington, DC: US Department of Health: Education \& Welfare, 1966.

CUNHA, N. M. Religiosidade e desempenho escolar: o caso de jovens brasileiros da região metropolitana de Belo Horizonte. 2012. 125 f. Dissertação (Mestrado em Economia) - Centro de Desenvolvimento e Planejamento Regional da Faculdade de Ciências Econômicas, Universidade Federal de Minas Gerais, Belo Horizonte, 2012.

FALLON, G.; BROWN, R. B. Focusing on focus groups: lesson form a research project involving a Ganbladeschi communit. Qualitative research Copyright (C) 2002 Sage Publications - London, Thousand Oaks, CA and New Delhi. v. 2, n. 2, p. 195-208. ago 2002.

FAZITO, D. Análises qualitativas na demografia: um exercício de autocrítca dos fundamentos e práticas no campo demográfico. In: MIRANDA-RIBEIRO, ANDREA; SIMÃO, A. (Org.). Qualificando os números: estudos sobre saúde sexual e reprodutiva no Brasil. 2. ed. Belo Horizonte: ABEP:UNFPA, 2009.

FRANCESCHINI, V. C. L.; MIRANDA-RIBEIRO, P.; GOMES, M. M. F. The color of school failure: factors associated with academic failure of high-schhol students. Educação e Pesquisa, São Paulo, v. 42, n. 3, p. 773-788, jul./set. 2016.

FRANCHIN, F.; BARRETO, S. M. G. Motivação nas Aulas de Educação Física: um enfoque no Ensino Médio. In: SEMINÁRIO DE ESTUDOS EM EDUCAÇÃO FÍSICA ESCOLAR, 1., 2006, São Carlos. Anais... São Carlos: CEEFE/UFSCar, 2006. Disponível em: <http://www.eefe.ufscar.br/pdf/fabiana.pdf>. Acesso em: 8 maio 2013.

GATTI, B. A. Grupo focal na pesquisa em Ciências Sociais e Humanas. Brasília: Liber Livro, 2005 .

GONÇALVES, M. E. Análise de sobrevivência e modelos hierárquicos logísticos lontigudinais: uma aplicação à análise da trajetória escolar $\left(4^{a}\right.$ a $8^{a}$ série - Ensino Fundamental). 2008. 140 f. Tese (Doutorado em Demografia) - Centro de Desenvolvimento e Planejamento Regional, Universidade Federal de Minas Gerais, Belo Horizonte, 2008. 
GUIMARÃES, R. R. de M. Probabilidade de progressão por série no Brasil: evolução, seletividade e aplicação de modelos de idade-período-coorte. 2010. 199 f. Tese (Doutorado em Demografia) - Centro de Desenvolvimento e Planejamento Regional, Universidade Federal de Minas Gerais, Belo Horizonte, 2010.

HOANG, T. N. The Relations between Parenting and Adolescent Motivation. International Journal of Whole Schooling, v. 3, n. 2, 2007. Disponível em: <http://www.eric.ed.gov/ PDFS/EJ847476.pdf>. Acesso em: 7 mar. 2011.

LEON, F. L. L.; MENEZES-FILHO, N. Reprovação, avanço e evasão escolar no Brasil. Pesquisa e Planejamento Econômico, Rio de Janeiro v. 32, n. 3, p. 417-451, dez. 2002.

MARE, R. Social Background and School Continuation Decisions. Journal of the American Statistical Association, v. 75, n. 370, p. 295-305, jun. 1980. Disponível em: <http://www. jstor.org/stable/2287448?seq=1\#page_scan_tab_contents >. Acesso em: 29 jun. 2015.

MIRANDA-RIBEIRO, P.; SIMÃO, A. B. Métodos qualitativos na demografia contemporânea: uma análise de conteúdo da produção científica em dois periódicos latino-americanos no século XXI. 2012. Disponível em: < http://alapop.org/2009/index. php?option=com_content\&view =article\&id $=1149 \& I t e m i d=561>$. Acesso em: 10 maio 2015.

MIRANDA-RIBEIRO, P.; SIMÃO, A. B. How far have we progressed? Qualitative research in demography during the 21st century. 2013. Disponível em: $<$ http://iussp. org/en/event/17/programme/paper/5685>. Acesso em: 10 maio 2015.

MORGAN, D. L. Focus Groups. Annual Review Sociol. v. 22, p. 129-152. 1996.

PONTES, A. N. et al. O ensino de química no nível médio: um olhar a respeito da motivação. In: ENCONTRO NACIONAL DE ENSINO DE QUÍMICA (XIV ENEQ), 14., UFPR. Anais... 2008. Curitiba/PR. Disponível em: <http://www.quimica.ufpr.br/eduquim/ eneq2008/resumos/R0428-1.pdf>. Acesso em: 8 maio 2013.

PORTO, I. C. M. G. Investigando a motivação de estudantes de Ensino Médio em relação à matemática. 2005. Disponível em: <http://www.ucb.br/sites/100/103/ TCC/22005/IsabelCristinadeMeloGPorto.pdf>. Acesso em: 8 maio 2013.

RESENDE, M. A. M. Por que escolas com características semelhantes apresentam resultados tão diferentes? 2005. 134 f. Dissertação (Mestrado em Educação) - Faculdade de Educação, Universidade Federal de Minas Gerais, Belo Horizonte, 2005.

RIANI, J. L. R. Determinantes do resultado educacional no Brasil: família, perfil escolar dos municípios e dividendo demográfico numa abordagem hierárquica e espacial. 2005. 234 f. Tese (Doutorado em Demografia) - Centro de Desenvolvimento e Planejamento Regional, Universidade Federal de Minas Gerais, Belo Horizonte, 2005.

RIANI, J. L. R.; RIOS-NETO, E. L. G. Background familiar versus perfil escolar do município: qual possui maior impacto nos resultados educacional dos alunos brasileiros? Revista Brasileira de Estudos Populacionais, São Paulo, v. 25, n. 2, p. 251-269, jul./dez. 2008.

RIBEIRO, R. A.; FONSECA, F. S. A.; SILVA, P. N. Estudantes do Ensino Médio e a motivação para estudar química. In: REUNIÃO ANUALDA SOCIEDADE BRASILEIRA DE QUÍMICA, 26., CONGRESSO LATINO-AMERICANO DE QUÍMICA, 27., 2004. Anais... Disponível em: <https://sec.sbq.org.br/resumos/27RA/T04542E1.pdf>. Acesso em: 8 maio 2013.

SILVA, C. R.; GOBBI, B. C.; SIMÃO, A. A. O uso da Análise de Conteúdo como uma ferramenta para a pesquisa qualitativa: descrição e aplicação do método. Organizações Rurais e Agroindustriais, Lavras, v. 7, n. 1, p. 70-81, 2005.

SOUZA, J. A expansão urbana de Belo Horizonte e região metropolitana de Belo Horizonte: o caso específico do município de Ribeirão das Neves. 2008. 194 f. Tese 
(Doutorado em Demografia) - Centro de Desenvolvimento e Planejamento Regional, Universidade Federal de Minas Gerais, Belo Horizonte, 2008.

VIEIRA, M. T. Relatório 6: Cálculo dos Pesos Amostrais para a Pesquisa de Avaliação do Programa Poupança Jovem (PJ) da Coorte de 2008 (Linha de Base) no Município de Ribeirão das Neves e Municípios Adjacentes (Produto 6). Centro de Desenvolvimento e Planejamento Regional (Cedeplar) da Universidade Federal de Minas Gerais. ago 2009.

\section{NOTAS}

${ }^{1}$ A segunda quinzena do mês de julho foi período letivo em 2014, devido à antecipação das férias escolares, que coincidiram com a Copa do Mundo do Brasil, realizada entre 12/06/14 e 13/07/14.

Submetido: 19/05/2015

Aprovado: 06/12/2016

Contato:

Vanessa Lima Caldeira Franceschini

Rua Bombaim, 133 Bairro Trevo

Belo Horizonte |MG |Brasil

CEP 31.370-220 